This is an early (post-review) version of:

Siegenthaler, Fiona (2013): "Towards an Ethnographic Turn in Contemporary Art Scholarship", in: Critical Arts: South-North Cultural and Media Studies 27(6), pp. 737-752. Special Issue: Revisiting the Ethnographic Turn in Contemporary Art, part 2. Guest editors: An van. Dienderen, Kris Rutten, Ronald Soetaert*

DOI: 10.1080/02560046.2013.867594

\title{
Towards an ethnographic turn in contemporary art scholarship
}

\begin{abstract}
While an ethnographic turn has indeed taken place in contemporary art practice, this is not necessarily the case with scholarly research in contemporary art. This is especially surprising considering the conditions under which research on contemporary art production takes place. The particular processuality of the artworks does not allow for an exclusive use of established methods in art history, but requires additional approaches.
\end{abstract}

This paper calls for an ethnographic turn in art scholarship that complements established approaches with methods and research questions derived from social anthropology and sociology, such as participation, observation, and qualitative studies in social and aesthetic production, reception and perception.

Artists working in the ethnographic modality normally seek social interaction, but scholarly analysis hardly considers the actual exchange taking place during the art project and both its social and aesthetic implications. In order to keep up with new artistic practices, art scholars need to adopt empirical approaches that go beyond the exhibition space and other sites of art mediation and take instead the factual social and aesthetic processes and impacts in the 'field' into consideration. These processes occur both during the project period and in its aftermath in both the artist's life as well as the life of the people or groups involved. Drawing attention to these social interactions and interpretations is necessary not only in the analysis of projects by 'northern' artists in 'southern' contexts, but in any art practice that involves and aims at social exchange.

Keywords: Contemporary art; process-based art; relational aesthetics; methodology; African art; ethnographic turn; transnational art 
Fiona Siegenthaler is a post-doctoral Researcher and Lecturer at the Institute of Social Anthropology, University of Basel and Research Associate at the Research Centre Visual Identities in Art and Design, University of Johannesburg. Fiona.Siegenthaler@unibas.ch 


\section{Introduction: New art practices necessitate new methods}

It has been almost twenty years since the publication of Hal Foster's groundbreaking essay The artist as an ethnographer in 1995. Much has happened since, both in social anthropology and contemporary arts. While his essay, and the criticism it triggered (see e.g. Green 1997, Rampley 2000), is still valid today, some aspects and perspectives of the mid-1990s need to be revisited in an attempt at locating or relocating them to the mid-2010s. At the time, Foster had combined two essential discourses taken from the diverse disciplines of ethnography and art history: institutional criticism in art and a post-colonial cultural critique of representation. By combining the crisis of representation with the analysis of institutionally critical artistic practices, he asked whether, and if indeed legitimately, artists may act as 'ethnographers,' although his understanding of 'ethnography' was certainly restricted.

This article undertakes a reconsideration of Foster's attempt at understanding art practice as a form of ethnographic practice and look at the implications for scholarly research. It will argue that his understanding of ethnography proceeded from a postcolonial cultural critique of the power of representation topical at the time, but largely ignored a quality central to the ethnographic discipline from its outset: its specific methods of observation and participation in the field. Focusing on artists who work within the framework of institutional critique, and considering their practice exclusively within museum spaces, his notion of ethnographic aesthetics is one of representation of the Other or the critique thereof. However, ethnographic aesthetics can be understood differently - as a particular method of research and experienced practice that leads beyond the representational framework of a museum into a social setting. Artists increasingly emphasise social practices, networks, and processes as constituting the actual artwork instead of the art object or its particular social, political, or institutional specificity. Events that facilitate social interaction and cultural encounter are variously seen as the actual art practice, and only sometimes do they acquire a concentrated and reflective documentation and representation in the exhibition space. This new art practice has two important consequences. Firstly, the 'museum' institution, or its critique, is no longer necessarily of concern to the artist. Rather, s/he merely uses it as a place to present/document practices normally of ephemeral and contingent character taking place beyond the museum walls. Secondly, if these art practices take place beyond the exhibition space and are actually entrenched in everyday social practices in a fundamental manner, scholars of contemporary art require new or rather additional methods. If contemporary art essentially defines aesthetic practices based on social practices, scholars need to extend their scope of aesthetic analysis to include that of social practice. This is why I call for an 'ethnographic turn' in art scholarship that actively seeks and practices methods derived from 
the social sciences and social anthropology. Such methods would include on-site participation and observation of such artistic events and everyday practices. In turn, the study of artwork and documentation in a museum context would not become obsolete. Instead, it is enriched by the fact that the researcher/critic is no longer limited to merely analysing the visual and textual documentation and the material residues of art practices taking place elsewhere. By adopting ethnological methods, art scholars both partake of and are involved in these artistic qua social practices, only then enabling them to trace their actual and factual aesthetic qualities.

\section{The 'ethnographic': From postcolonial critique of representation to an interest in practices}

\section{and processes}

Institutional critique peaked in the USA in the mid-1990s. Artists such as Daniel Buren referred to the not-so-neutral, indeed highly representational and political exhibition space itself, and Louise Lawler or Sherrie Levine appropriated established icons of the art world to re-produce them in the exhibition space, seeking to interrogate the value and (re)production system of art works on the global art market. Others, such as Hans Haacke or Lothar Baumgarten, hinted at political and social issues occurring beyond the museum walls, in local politics or 'other' places traditionally in the purview of social anthropology and now attracting the interest of cultural producers, artists and curators alike, who were opening their institutional doors to contemporary non-Western art. These artistic interests in the social 'other,' and particularly in the history of Othering, formed part of a rather late postcolonial critique that gained presence in the nineties through scholars such as Edward Said (1978), Homi Bhabha (1994) or Achille Mbembe (2001). These cultural theorists and postcolonial scholars directed the artists' attention to the disciplinary and representational history of social anthropology, not to the ethnographic literature which had attracted greater artistic attention in the 1960s and 1970s. Hal Foster's essay must be located in the context of this institutional and postcolonial criticism, rather than the discipline of social anthropology itself. This is most obvious when we try to understand what it is Foster refers to with the term 'ethnographic,' and as Renée Green has demonstrated, it is almost impossible to do so: he uses the term as a notion rather than as an exact description of a particular property or practice (Green 1997: 154), and this notion appears to relate in some manner mostly to practices of Othering. This use of a particular term with long-standing scholarly tradition for practices somehow relating to the 'Other' or that has evolved from a cultural critique within contemporary art practices, obviously leaves many questions unanswered. What, exactly, does Foster mean by the term ethnographic? What, in his eyes, is characteristic of ethnography and ethnographic practice? In what relation does this stand to the scholarly notion of ethnography? This in turn leads to essential questions concerning artistic practices and to a greater degree, to the practices 
of the art historian discussing them. Depending on what 'ethnographic' is taken to mean, very different art practices are subsumed by or excluded from this term, with each practice enabling the art critic and the art scholar with different approaches.

In the 1990s, art predominantly occurred within the institutional framework of the museum and exhibition spaces, even if it hinted at social and political contexts and practices beyond the museum walls. These Foster emphasises when talking about the artist as ethnographer:

[A] new ethnographer envy consumes many artists and critics. If anthropologists wanted to exploit the textual model in cultural interpretation, these artists and critics aspire to fieldwork in which theory and practice seem to be reconciled. (Foster 1996: 181)

However, paradoxically, Foster bases his analysis of artistic practices 'in the field' on the museum exhibits as the material and visual results derived from this artistic research. Moreover, the artists he selects to substantiate the claim of artistic 'fieldwork' speak of practices quite distinct from that of direct social engagement in the social field, or even within institutions. Indeed, Foster eschews discussing artists whose practice is based on the social interaction with diverse social groups and that frequently interrelates with public aesthetic interventions. Rather, he discusses artists who take as their subject the (hi)stories of representation, ethnographic literature, and topical discourses on Othering and reflect these in the exhibition space. As he understands it, the 'artist as ethnographer' struggles with the image, the imaginary, and the representation of the Other, but within the protected arena of the exhibition space and which, in doing so, becomes subject to institutional and representational critique:

In this new paradigm the object of contestation remains in large part the bourgeoiscapitalist institution of art (the museum, the academy, the market, and the media), its exclusionary definitions of art and artist, identity and community. (Foster 1996: 173)

This he exemplifies with artists such as Renée Green and Adrian Piper, who attempt to deconstruct representations of the Other, of black, female, or gay identities through their use of representational tools, including newspaper clippings, documents, diaries, scientific materials, etc. Correspondingly, their interests lay with deconstructing and critiquing colonially informed representations and not the social practices of the Other. Describing 'ethnographic' artistic practices in this way, it is unsurprising that he sees a "danger, for the artist as ethnographer, of 'ideological patronage'” (Foster 1996: 173). ${ }^{1}$ To this end, he places his focus on artists who specifically remain within a representational framework by reflecting on the representation of the Other and the practice of Othering within an exhibition space. In this he limits himself to artists

\footnotetext{
${ }^{1}$ Later in his text, Foster includes Fred Wilson and Andrea Fraser as examples to show that even what appears as institutional critique serves to legitimate the institution, especially where it is the institution commissioning such projects (Foster 1996: 191-196).
} 
who elaborate notions of representation by placing, themselves, representational media and imagery in one of the most representational types of Western hegemonic cultural spaces of the last two centuries, the museum. ${ }^{2}$

In her excellent critique of Foster's essay, Renée Green (1997) perceptively registers that only a few artists working in the 'ethnographic' idiom he claims to observe in contemporary art are named, and that their work is discussed only superficially (Green 1997: 155). He further fails to outline the particularities of this 'ethnographic' approach (Green 1997: 154; Rampley 2000: 13), mainly in the sense of what is the task and practice of the ethnographic discipline beyond mere Othering or the critique thereof. His theorists of preference are George Bataille and Aimé Césaire as well as the not very representative ethnographer Michel Leiris when substantiating his argument of an 'ethnographic' practice as a practice of Othering (Foster 1996: 175). It is obvious that Foster's notion of ethnography derives from the then topical cultural and scholarly critique of a modernist ethnographic tradition of Othering most prominently advocated by James Clifford whom he explicitly names (Clifford \& Marcus 1986; Clifford 1988). Foster's 'Other' appears at times even more 'Other' even than that of the criticised ethnographic legacy. Green makes this observation when she notes that he completely neglects contact zones, co-presence, and transculturation as a positive side of the ethnographic encounter (Green 1997: 155-156).

However, ethnography's aim is not merely to denote oppressed, subaltern, or distinct marginalised cultures as 'Other,' nor does it aim to merely criticise such practices. Foster avails himself of an archetypal image of the anthropologist common to the practice of deconstructing the dominant ethnographic discourses during the 1980s and the early 1990s, the era marked for its 'crisis of representation' (Berg \& Fuchs 1993). Both Akhil Gupta and James Ferguson (Gupta \& Ferguson 1997a: 11-12) eloquently describe and critically discuss this archetype. Like many of his contemporaries, Foster appears to equate ethnographic practice to a kind of 'bad practice,' calling anything 'ethnographic' that has to do with Othering and representational critique. In an interview with Alex Coles, Clifford reflects on this tendency:

Of course all methodologies, which in interpretive/historical studies are always modes of partial translation, first get you somewhere and then run out of gas. 'Ethnography', whether in its strict anthropological or expanded cultural-critical sense, is no exception: it involves recognition and mis-recognition. Hal Foster, reacting against its sometimes uncritical popularity in art practices of the early 1990s, cuts 'ethnography' down to size. And in this he's part of a necessary counter-trend [...]. But I would caution readers of

\footnotetext{
${ }^{2}$ This adherence to representation is the problem Foster alludes to when he writes: "Just as the elaboration of psychoanalysis and anthropology was fundamental to modern discourses (modernist art included), so the critique of these human sciences is crucial to postmodern discourses (postmodernist art included) [...]. Yet this critique, which is a critique of the subject, is still centered on the subject, and it still centers the subject." (Foster 1996: 178)
} 
Hal's several pages (in The Return of the Real) on 'the new anthropology' that he provides a very truncated account [...]. And in a common dismissive move, the new anthropology is reduced to textualism and hyper reflexivity. (Coles \& Clifford 2000: 5657)

Foster disregards the qualities and aims of the ethnographic methods that had found their way into artistic practice in a highly creative and productive way at the time of the essay's publication. He is certainly right to criticise projects that seem to bear an ethnographic approach while ignoring some of its fundamental aspects (Foster 1996: 196). For the main part, his criticism focuses firstly on the fact that the decision on what is finally exhibited remains exclusively with the artist and secondly that the community collaborating with the artist'ethnographer' is very rarely engaged or involved in the mode of representation resulting from this collaboration. This critique is absolutely legitimate. However, it should also include the reflexive question addressing whether the scholar/art critic's attention is not better directed at the interaction taking place during such processes rather than the objects exhibited within the representative spaces of the museum. For this reason, the following discussion focuses on these new practices, which have more in common with the discipline of ethnography and its specific methods than the asserted tendency of Othering (or its de-construction).

\section{Art as social space}

The ethnographic turn today, I contend, has its basis neither in practices of radical Othering nor in its merely discursive critique and, most importantly, has effectively left the representational museum space behind. In its place, the actual quality of field research (proximity and direct experience that cannot be objectified but only experienced subjectively in an 'embodied' manner) has become an essential aspect, not only of social anthropology, but also of contemporary art practices. Social and cultural experiences as such increasingly form a central aspect of the artists' aims, frequently finding expression in extended travelling and physical as well as internet-based networking.

A popular desire and practice of contemporary art is encountering the Other (people, cultures, societies) with the aim of familiarisation and to generate new communities. Nicolas Bourriaud (2002) has described many of these practices as 'relational art,' which is constantly developing new forms, concepts, and ideas. More fitting, perhaps, in describing the underlying principle of these practices, is art historian Nina Möntmann's notion of art as 'social space', or of the artwork as a space of agency [Handlungsraum] (Möntmann 2002). Rather than criticising the museum's representational function and thereby effectively remaining within this very space, art as a social 
space creates interactions (Möntmann 2002: 128). In this sense, art is not so much situated in, but the generator and producer of a social space (Möntmann 2002:129).

Such social spaces, argue spatial theorists Michel de Certeau (1988) and Henri Lefebvre (1974), derive from the unfolding relationships between actors and places. They are constituted by social actions (Möntmann 2002: 125-133). This shift to agency and relationality as the producer of space emphasises action and process as opposed to the physical expanse of place and site. Moreover, this also changes the political quality of spaces, representational as well as others: Though they are still highly political spaces, they exist as spaces of social networking, not of opposition, of lived relations not conceptual polarities (Möntmann 2002: 126). With this new emphasis on social processes instead of representational spaces, the museum loses its significance as a place of aesthetic experience (albeit not of value production and artistic career promotion). This Möntmann extensively describes in her discussion of Rirkit Tiravanija, who in the 1990s converted exhibition spaces to living spaces or gallery offices to kitchens where he (or his double) catered for guests. He created social spaces within the confines of the institutional space that targeted audiences and practices in their everyday existence. More importantly, he not only transforms spaces, thereby marking them as Other, he also activates them for social and societal use. Only with the actions and interactions of the attendant people do the spaces come into being. A further practice, exemplified by René Green, is the migrant or itinerant artist who turns the place where s/he is temporarily at into the research, production, and exhibition space (Möntmann 2002: 133-154). Such agency-based, processual art practices most often transpired or crystallised during the opening of an exhibition or its display in an art space, for instance a museum. Krzysztof Wodiczko, for instance, spent much of his time in New York collaborating with homeless people on his Homeless vehicles (1987-1989). He met with people living on the streets to discuss their needs and ideas and how they best be accommodated. The actual vehicles as well as the sketches and photographs resulting from this research process were (and still are) shown in exhibition spaces. These documents provided an opening for social issues. However, the actual social exchange and the practice of communication and cooperation took place beyond the museum space.

It is striking, even incomprehensible, that Foster explicitly excluded artists like Wodiczko from his discussion of 'artists as ethnographers' (Foster 1996: 172). This exclusion is surprising, not for the artist's interest in the (social) Other, but for Foster's disinterest in the actual art practices that engage the social actions in urban spaces. Instead, he favours the 'site-specific' installations in museum spaces which frequently allude precisely to those social practices prevalent beyond its confines (Foster 1996: 172). 


\section{Scholarly research in process-based and socially interested art practices}

In recent years, artists and artist groups such as Alfredo Jaar or the Invisible Borders association have expanded their interests in cultural contexts as an actual art practice. They are interested in new encounters, cultural exchange, social networking, and a permanent verbal, artistic, and physical conversation with others that may be based in ethnically or socially different cultures, but do not necessarily do so. They seek a long-term exchange and a way of getting to know and understand each other. Often, their practices include ways of gaining an introduction to the societies or communities of other artists, or of introducing others to their own social spheres. These artists are not obsessed with a "primitivist fantasy" (Foster 1996: 175), but are aware of the Other as a cultural construct. They are interested in encountering the 'Other' as an individual, a colleague, a brother in arms, and a person with whom s/he shares ideas, artistic or personal interests and a social as well as an art-related practice. Though this exchange will take place on every level of social relationships that artists maintain, some explicitly reflect such social and creative relations and practices in their art practice. These artists consider their art practice and the resulting relationships and contacts as being embedded in an international and sometimes even global network. Hence, travelling familiar and foreign lands has become very popular among artists, even more so in regions without easy travel access such as many countries in the Global South. The 'itinerant artist' or the artist nomad appears to be emerging as a new type of artist who makes other places and people, especially the encounter with these, their actual working material. They are not seeking solitude but instead identify with groups and collectives, whose individual members specialise in different genres and media. Their interest lies with the commonality and exchange of moments experienced, with journeys and residencies rather than the reflection of the self in the Other (Meyer 2000). In fact, Foster even mentions the more recent trends in artistic practice that can be described as "relational" and process-based (Bourriaud 2002), but he does not discuss them (Foster 1996: 178). As a consequence, he also ignores the possible implications such art practices have for art scholarship.

In the following, two examples of socially interested and process-based art are presented with first, an intervention by Alfredo Jaar and second, the Invisible Borders project. They certainly do not represent the entire range, but offer a glimpse into important aspects of these art practices and their significance for an ethnographic turn in contemporary art scholarship.

In The Cloud (2000), Alfredo Jaar engaged groups of people to challenge the militarised national border between Mexico and the USA. These prevent immigrant workers from crossing the physical borders to a newly 'globalised' market and frequently result in their dying in the attempt. He offered bereaved families and parties affected by this militarised border situation a 
physical space and a 45-minute period at either side of the fence to mourn the lives lost and to find solidarity in the group. Though certainly a symbolic act (which included letting off balloons that unexpectedly chose to fly towards Mexico), it also brought together people who shared a common experience or a political interest, thereby facilitating future social relations and interactions. $^{3}$

While the art work had an immediate social and aesthetic impact on place, what remains in its documentation is mainly its symbolic gesture. There is no information on the factual effects of this event firstly on the life of the people involved and secondly on local social and cultural practice. Have people decided to continue with such meetings, independent of the presence of the artist? Has the event initiated a more public discourse about border victims? Has the artist sourced from or fed into local practices of mourning? Or is it possible that this event barely played a sustainable role locally while its documentation is strongly received in the global art world? Such questions that lead beyond the mere symbolical meaning of the act can only be asked and answered through research on place; during and after the event. If we aim at understanding the social and aesthetic relevance of the work on site, its meaning for the people involved, research must be conducted that includes observation and participation during the event, discussions and conversations with the participants in the aftermath of the project, and research in local practices of commemoration that situates the art work in relation to them.

Interventions like The Cloud may be singular and isolated, but there are other long-term projects taking place. More recently, especially in Western Africa, groups of artists, designers, photographers, and related professionals come together in travelling teams that make their journey through the continent an essential part of their actual art work. One such group, Invisible Borders Trans-African Photographers Organisation, a loose association of Nigerian artists founded in 2009, describes its mission on its website as follows:

The vision of the initiative is to become a symbol of networking and transborder associations within the arts and photography in Africa, but also to become a stepping-stone platform for young immerging [sic] talents in the continent in such a way that it creates a breeding ground for young artist [sic] to be thinking beyond borders at the beginning stage of their creative quest. ${ }^{4}$

One of their main activities, road trips across Africa and transgressing national borders, they define as an actual artistic practice. On such trips, their aim is

to explore and participate in various photographic events, festival [sic] and exhibitions while engaging on a daily basis with the environment and the people encountered. The

\footnotetext{
${ }^{3}$ More on Alfredo Jaar, see the numerous monographs and his personal website: http://www.alfredojaar.net/.

${ }^{4}$ Website of Invisible Borders: http://invisible-borders.com/about-us/about/.
} 
emphasis is primarily on the collective journey of the participating artists who, during their momentary stops in capital cities, create photographic, video and textual works that often reflect their individual approach to engaging with local artists, art practitioners and the inhabitants. ${ }^{5}$

Their encounters, workshops, and visits with other artists on the continent and elsewhere form a contribution to creating, maintaining, and exploring art networks, while asserting their presence in the international art world, a practice certainly due in parts to the scarcity of art museums and exhibition spaces on the African continent. They explicitly seek out connections to the social contexts in which they are travelling:

We can therefore see the Invisible Borders Road trip [sic] as a workshop of artistic creation and a performative social intervention all rolled into one. Moreover it offers that unique experience of 'learning in motion' and discovering oneself through interactions with diverse encounters by constantly altering one's own reality through constant movement. ${ }^{6}$

During repeat visits on their annual road trip, they maintain and expand these contacts and the network. Thus, by navigating the geographical space, they create and shape social spaces and learn about other places and cultures that inform their own social and artistic practices. Many of these groups include artists from other continents, as was the case with Exit Tour, a road trip from Cameroon to Senegal. The trip, initiated and undertaken by six Cameroonian and one Swiss artist, took place in anticipation of the Dakar Biennale in $2006 .{ }^{7}$ In this, the experience of an 'other' context could be said to have been doubled in the sense that not only did the Cameroonian artists encounter the inhabitants from other African states, but the Swiss artist effectively adopted the art practices and social dynamics of the Cameroonian artists. Numerous such initiatives abound (for e.g., Scénographies Urbaines), frequently supported by international cultural or social funding that follow similar concepts of creating, networking, and performing in particular settings. ${ }^{8}$ These initiatives always demonstrate a sense of site specificity and awareness for the cultural contexts in which the artistic interventions take place.

For many artists and artist groups the modes of exhibiting such relational and processual practices in the representational space of a museum or project space pose a challenge, especially in regions with few or no institutions for the visual arts. This is due not least to the fact that they emphasise exchange as an actual artistic practice and not the institutional representation of these practices along with their findings. To translate these concepts and experiences into a thoughtful and aesthetical exhibition object or installation generally results in the production of a rather

\footnotetext{
5 Ibid.

${ }^{6}$ Ibid.

${ }^{7}$ Website for Exit Tour: http://www.dunjaherzog.org/index.php/?cat=62.

${ }^{8}$ Website of Scénographies Urbaines: http://www.eternalnetwork.org/scenographiesurbaines.
} 
modest and unexciting documentation, mapping, and presentation of photographs and sketches. Because such exhibitions lag behind the actual interactional practices and experiences, many of these initiatives choose other platforms to reflect on such social interaction and to share their experiences with other artists, the website and the blog featuring prominently as a solution.

However, art scholarship and art criticism continue to expect and seek much of the material they require in exhibition spaces. Here, the scholar or critic who is not part of the respective artist group sees no more than the photographs or what s/he hears or reads of the artists' narrative of the event. The risk museum audiences, scholars, and critics run with process-based art, which itself creates social spaces (often temporary and far from the museum), is to engage not with the artwork itself, but with its documentation and residuum. Consequently, the many social encounters and the actors integral to the project (as social agents) become invisible in the museum's representational space. The social exchange can effectively only be communicated to a limited degree, while long-term social and aesthetic consequences completely slip from sight. By contrast, knowing the relationship of such process-based art practices to the audience beyond the museum wall would convey much of the art's social and aesthetic engagement. This would include the artist's factual practices and ideas as well as the interests of the 'audiences' involved with the ephemeral artistic/social interactions. Just because these interventions are of a social nature and aim beyond the established art world, they entail new aesthetic modes and at the same time have (varying) impact on local social and cultural practices. For instance, several artist groups in African cities are inspired by the Invisible Borders project and launch similar initiatives, albeit adapted to their particular situation. It is obvious that, on a longer term, such projects have an impact not only on artistic practice, but also on social practice, on particular places they visit and people they encounter.

If artists seek new places, relations, and audiences, the researcher, in order to understand their aesthetic relevance, must adapt and move beyond the museum walls into the social and cultural context in which these projects take place. Process-based and relational art practices, then, require methodological adjustments borrowed from ethnology and other social sciences.

\section{Towards an ethnographic turn in contemporary art scholarship}

While art practices have shifted their focus from the representational space to the social space of interaction, the scholarship on these practices has hardly followed suit. While the artists travel and collect information on foreign places and cultures or navigate (or even create) new social contexts, the art critic and art historian tend to remain stationary within the confines of academia, the museum, or biennials and art fairs. They perpetuate the assumption that there, the exhibited 
work should not only be artistically valuable, but culturally sensitive, politically informed, and aesthetically convincing. The question that needs to be asked, however, is: Can artwork based on extensive research, travelling, and social involvement be judged on the basis of its presentation in an exhibition space? How do we deal with art that underscores processual and social practices and not the visual object? It would seem art criticism must extend its approach and methods to include not only an analysis of the artist's project description, possibly along with some biographical information and a few artist interviews. It must also develop a sensibility for, and interest in, the experience and the social and aesthetic impact of the process itself.

The frequent lack of actual art objects, or even documentation adequate for museum display, requires different modes of first-hand experiences of the artwork, that is: its observation and participation in both the moment of the processual and often interactive making and its aftermath. In approaching and addressing this problem, I am proposing to move beyond Foster's use of the term 'ethnographic' as a representational practice of Othering (or its critique) and propose the particularity of an ethnographic method.

Given the interactive, socially engaged, spatial and temporal particularity as well as the ephemeral nature of the described art practices, a subsequent question must address whether the scholars engaging with such practices should be as mobile as their object of research. The 'situation,' then, is not linked to the museum space but is part of the art practice as a social and analytic practice. The temporal, local, and mainly relational setting is a crucial aspect in such a practice. Because of its social embeddedness, this situatedness has much in common with the situation in which contemporary ethnographers find themselves. Akhil Gupta and James Ferguson, reflecting on what actually constitutes contemporary ethnography, emphasise neither Otherness nor research on unequal power relations (unlike Foster), but the methods specific to this discipline, such as participation and observation:

The difference between anthropology and [...] other disciplines, it would be widely agreed, lies less in the topics studied (which, after all, overlap substantially) than in the distinctive method anthropologists employ, namely fieldwork based on participant observation. In other words, our difference from other specialists in academic institutions is constructed not just on the premise that we are specialists in difference, but on a specific methodology for uncovering or understanding that difference. (Gupta \& Ferguson 1997a: 2)

In considering the term 'field' and its charged history, Gupta and Ferguson propose the use of the alternative term location. ${ }^{9}$ Unlike the field, which evolved within the context of natural

\footnotetext{
${ }^{9}$ For a thorough discussion and analysis of this loaded history closely associated to the discipline's history, see Gupta/Ferguson 1997.
} 
history which anthropology separated from at the beginning of the $20^{\text {th }}$ century, location includes a disciplinary reflexivity that social anthropology has intensified since the crisis of representation in the 1970s:

[W]e propose a reformulation of the anthropological fieldwork tradition that would decenter and defetishize the concept of 'the field,' while developing methodological and epistemological strategies that foreground questions of location, intervention, and the construction of situated knowledges. [...] With this in mind, it seems most useful to us to attempt to redefine the fieldwork 'trademark' not with a time-honored commitment to the local but with an attentiveness to social, cultural, and political location and a willingness to work self-consciously at shifting or realigning our own location while building epistemological and political links with other locations. (Gupta \& Ferguson 1997a: 4-5)

By calling for a locational reflexivity, Gupta and Ferguson emphasise that the ethnographic practice is not based on an imaginary 'distant place,' the Other or the Exotic, but can easily take place in the ethnographer's immediate vicinity:

Perhaps we should say that, in an interconnected world, we are never really 'out of the field.' (Gupta \& Ferguson 1997a: 35)

This concept of location allows access to "situated knowledges" (Haraway 1988). Such 'knowledges' are neither temporally nor spatially fixed, but evolve from diverse factors that include local and other sources. These depend on social practices and their relationality to local as well as transnational and global aspects that shape local culture and vice versa. Hence, 'field research' as an ethnographic method and adapted as a 'locational' understanding of both the social practices being researched and the researcher himself or herself, is a promising approach to the new art practices focusing on the analysis and creation of social space through intervention, interaction, process-based collaboration and a permanent maintenance, activation, and expansion of social networks.

\section{Conclusion}

What do these insights imply for contemporary art scholarship? First and foremost, it no longer suffices to merely assert a 'relational aesthetics' and an ethnographic method for contemporary artistic practices without moving beyond the artworks exhibited and displayed within the museum. The art scholar's field research must effectively move beyond the museum locus to an expanded field of art practices. This is especially the case where they are inseparable from social practices. Artists conversant in art theory, institutional critique, and the history of ethnographic representation as well as its cultural mediation, such as Green, Kruger, or Durham, are certainly able (though not always willing) to set up an exhibition providing viewer and scholar the aesthetic and theoretical reflexivity s/he expects and hopes to see. Though a generous gesture, it 
underscores the extent to which Western ideas of aesthetics, criticality, and education through art continue to inform art scholarship. Once art takes place in social exchange, in the lived transgression of cultural or institutional borders, and in projects that are ephemeral rather than object-based in nature, art scholars need to expand their questions and consider participation, observation, long-term cohabitation, interviews and informal conversations as part of their research methods. Without this, the art practices are not sufficiently perceived, received, nor acknowledged. Foster's essay is a perfect example. Though he makes general reference to the social sensibility of the artists discussed, he excludes their actual social and political practice beyond the museum confines within their locational context. He prefers to focus on what is found in the museum. As a consequence, he only alludes to the fact that social interactions have taken place in the background, but he is unable to describe them as a process and practice with any inherent aesthetic value.

One of the major problems in art scholarship and criticism is the fact that we often need to deal with the leftovers, sketches, conceptual texts, and manifestoes when we actually want to reflect and write on the practices and processes underlying these objects exhibited. This applies even more when dealing with artists emphasising social processes and creating social spaces, artists who spend time with people, participate in their everyday life as they dive into and even embody or appropriate the social and cultural experience without the constraints of staging this very process in any representational space. Such art, made through the process of social interaction and cooperation, needs to be explored, documented, commented, and analysed in the very process of being lived. Hence, the museum visit may be part of the research, but the main focus of scholarly research must rest with the artist's location. Only in this way can art historians truly contextualise the artistic practice, understand the relational constellations in which it occurs and which, in turn, it creates. By introducing ethnographic methods to their research practice, art scholars can begin to approach an understanding for practice-based, performative, relational, and ethnographic art practices and their relevance for audiences beyond the art institutions. In doing so, the art researcher's positionality and location is radically changed and requires the point of view and perspective to be reconsidered based on the inhabited location. The researcher is forced to recognise that $\mathrm{s} / \mathrm{he}$ is as much part of site-specific and relational networks and contexts as is the artwork. Such an awareness of location, finally, only unfolds through the movement and experience of "one place after another," as Miwon Kwon calls her book on site-specificity, locational identity, and the reality of migrating worlds (Kwon 2002). These worlds do not necessarily require the dated ethnographic perspective from an auctorial North looking down onto a (post)colonial South. This is a multidirectional gaze adhering to the factual flow of the 
practices and social networks unfurled by contemporary artists worldwide. By zooming in on particular projects and their relational functioning, such practices can be investigated more deeply (or "vertically" as Foster [1996: 199] puts it) to understand what is occurring on the "horizontal" level of the expanded art practice and its scholarly research fields. Reflected in this apparently superficial 'horizontal level' is the entire depth of today's art practices extending beyond the museum space's representational realm.

Finally, an ethnographic approach to contemporary art practice does not only contribute to the understanding of socially interested process-based arts. It also establishes new perspectives on those art genres that do not explicitly address (or indeed aim at) social interaction and its exploration and establishment of networks. New perspectives, questions, and insights may occur as we contemplate object-based art genres, as at once situated in and generating a social space, including the museum space. They are necessarily embedded in social contexts, even if they appear to adhere to ideas of the autonomous artwork or site-specific interventions in museum spaces in Foster's sense. Their social and aesthetic quality (as one emerging from and feeding into art production, perception and reception) then reveals new insights into their very role, function, and meaning within the society in which they partake.

\section{References}

Berg, E. and M. Fuchs (eds.). 1993. Kultur, soziale Praxis, Text. Die Krise der ethnographischen Repräsentation. Frankfurt a. M.: Suhrkamp.

Bhabha, H. 1994. The location of culture. London: Routledge.

Bourriaud, N. 2002. Relational aesthetics. Dijon-Quetiny: Les Presses du Réel.

Clifford, J. 1988. The predicament of culture: twentieth-century ethnography, literature, and art. Cambridge: Harvard University Press.

Clifford, J. and G. E. Marcus (eds.). 1986. Writing culture: the poetics and politics of ethnography. Berkeley: University of California Press.

Coles, A. (ed.). 2000. Site-specificity: the ethnographic turn. London: Black Dog Publishing.

Coles, A. and J. Clifford. 2000. An ethnographer in the field. James Clifford interview. In Sitespecificity: the ethnographic turn, ed. A. Coles, 52-73. London: Black Dog Publishing.

De Certeau, M.1988. Die Kunst des Handelns. Berlin: Merve Verlag. 
Foster, H. 1996. The artist as ethnographer. In The return of the real: the avant-garde at the end of the century, ed. H. Foster, 171-203. Cambridge/London: MIT.

Green, R. 1997. Der Künstler als Ethnograf? Texte zur Kunst 7(27): 152-161.

Gupta, A. and J. Ferguson (eds.). 1997. Anthropological locations: boundaries and grounds of a field science. Berkeley/Los Angeles: University of California Press.

Gupta, A. and J. Ferguson. 1997a. Discipline and practice: 'the field' as site, method, and location in anthropology. In Anthropological locations: boundaries and grounds of a field science, eds. A. Gupta and J. Ferguson, 1-46. Berkeley/Los Angeles: University of California Press.

Haraway, D. 1988. Situated knowledges: the science question in feminism and the privilege of partial perspective. Feminist Studies 14(4): 575-599.

Kwon, M. 2002. One place after another: site-specific art and locational identity.

Cambridge/London: MIT Press.

Lefebvre, H. 1974. La Production del'Espace Paris: Anthropos.

Mbembe, J. A. 2001. On the postcolony. Berkeley: University of California Press.

Meyer, J. 2000. Nomads: figures of travel in contemporary art. In Site-specificity: the ethnographic turn, ed. A. Cole, 10-26. London: Black Dog Publishing.

Möntmann, N. 2002. Kunst als sozialer Raum. Cologne: Verlag der Buchhandlung Walther König (Kunstwissenschaftliche Bibliothek 18).

Rampley, M. 2000. Anthropology at the origins of art history. In Site-specificity: the ethnographic turn, ed. A. Cole, 138-165. London: Black Dog Publishing.

Said, E. W. 1978. Orientalism. London: Routledge.

\section{Websites}

Invisible Borders. About. Accessed 25.2.2013. http://invisible-borders.com/about-us/about/. Invisible Borders. Blog. Accessed 25.2.2013. http://invisible-borders.com/category/blog/. 
Exitour. Website by Dunja Herzog replacing the original blog. Accessed 25.2.2013.

http://www.dunjaherzog.org/index.php/?cat=62.

Scénographies Urbaines. Accessed 25.2.2013.

http://www.eternalnetwork.org/scenographiesurbaines.

Alfredo Jaar. Accessed 25.2.2013. http://www.alfredojaar.net/. 